\title{
Pengaruh Berbagai Jenis Pupuk Organik dan Fungi Mikoriza Arbuskula Terhadap C-Organik Tanah, Pertumbuhan dan Hasil Tanaman Jagung Semi (Zea mays L.)
}

\section{Effect of Various Types of Organic Fertilizers and Arbuscular Mycorrhizal Fungi on C-Organic Soil, Growth and Yield of Semi Corn (Zea mays L.)}

\author{
Neng Fika Nurhakiki, Kiki Zakiah, Atak Tauhid \\ Program Studi Agroteknologi, Fakultas Pertanian Universitas Garut \\ Jalan Raya Samarang 52A, Tarogong Kaler, Garut, Jawa Barat \\ e-mail : ataktauhid@uniga.ac.id
}

\begin{abstract}
ABSTRAK
Penelitian ini bertujuan untuk mengetahui pengaruh berbagai jenis pupuk organik dan Fungi Mikoriza Arbuskula (FMA) terhadap C-organik pertumbuhan dan hasil tanaman jagung semi. Percobaan dilakukan di Desa Sukarasa, Kecamatan Samarang, Kabupaten Garut, Jawa Barat, dari Bulan Februari sampai Bulan April 2018. Ketinggian tempat 1500 meter di atas permukaan laut. Metode penelitian yang digunakan adalah metode eksperimental, dengan menggunakan Rancangan Acak Kelompok (RAK) berpola faktorial 3 x 3 dengan tiga ulangan. Faktor pertama adalah dosis pupuk organik (o) terdiri atas tiga taraf, yaitu $\mathrm{o}_{1}=$ pupuk kandang ayam $210 \mathrm{~g} / \operatorname{tanaman}, \mathrm{o}_{2}=$ pupuk kandang sapi $210 \mathrm{~g} / \operatorname{tanaman}, \mathrm{o}_{3}$ = pupuk kandang domba $210 \mathrm{~g} /$ tanaman. faktor kedua dosis (FMA) (m) terdiri atas tiga taraf, yaitu $\mathrm{m}_{1}=2 \mathrm{~g} /$ tanaman, $\mathrm{m}_{2}=4 \mathrm{~g} /$ tanaman, $\mathrm{m}_{3}=8 \mathrm{~g} /$ tanaman. Hasil penelitian menunjukan tidak terjadi interaksi antara berbagai jenis pupuk organik dan (FMA) terhadap C-organik, pertumbuhan dan hasil jagung semi. Pengaruh dosis pupuk kandang sapi $210 \mathrm{~g} /$ tanaman dan mikoriza $8 \mathrm{~g} /$ tanaman memberikan nilai yang paling tinggi terhadap tinggi tanaman, luas daun, bobot tongkol pertanaman.
\end{abstract}

Kata kunci : pupuk organik, Fungi Mikoriza Arbuskula, jagung semi

\begin{abstract}
This research aims to study the effect of various types of organic fertilizers and Arbuscular Mycorrhizal Fungi (AMF) to organic-C growth and yield of baby maize (Zea mays L.). The experiment was conducted in Sukarasa Village, Samarang District, Garut Regency, West Java, from February to April 2018. The altitude is 1500 meters above sea level. The research method used was experimental method, using Group Randomized Block Design (RAK) $3 \times 3$ pattern with three replications. The first factor was various types of organic fertilizer $(o)$
\end{abstract}


consisting of three levels, namely o1 = chicken manure equal to $210 \mathrm{~g} /$ plant, o2 $=$ cow manure equivalent to $210 \mathrm{~g} /$ plant, $\mathrm{o} 3=$ sheep manure $210 \mathrm{~g} /$ plant . the second factor was AMF dose $(\mathrm{m})$ consists of three levels, namely $\mathrm{ml}=2 \mathrm{~g} / \mathrm{plant}$, $m 2=4 \mathrm{~g} /$ plant, $m 3=8 \mathrm{~g} /$ plant. The results showed: there was no interaction between various types of organic fertilizers and $(A M F)$ to organic- $C$, baby-growth and yield of baby corn. The effect of dosage of cow manure of $210 \mathrm{~g} /$ plant and mycorrhizal $8 \mathrm{~g} /$ plant gives the highest value to plant height, leaf area, cob weight of cropping.

Keywords: organic fertilizer, arbuscular mycorrhizal fungi (FMA), baby corn.

\section{PENDAHULUAN}

Pengusahaan jagung semi di Indonesia lebih banyak dari hasil sampingan tanaman jagung yang ditanam pada musim kemarau. Permintaan pasar tidak dapat dipenuhi akibat produksi yang tidak kontinu dan mutu yang belum terjamin. Agus (1994) memaparkan bahwa permintaan pasar dalam negeri terhadap jagung semi pada kota-kota besar dapat mencapai 15 ton per hari, untuk memenuhi permintaan jagung semi yang terus meningkat maka para petani melakukan budidaya secara khusus. Produktivitas jagung semi yang tinggi, perlu ditunjang oleh beberapa faktor varietas yang unggul dan kondisi tanah yang baik. Kondisi tanah yang ideal untuk jagung adalah gembur, subur, berdrainase baik, ketersediaan air baik, kemiringan tanah kurang dari $8 \%$ dan yang paling penting yaitu kandungan unsur hara N, P, K dan C-organik yang optimal.

Kandungan C-organik lahan pertanian yang sangat rendah merupakan akibat dari pengolahan tanah yang intensif dengan unsur kimiawi tanpa memperhatikan kelestarian tanah yakni usaha pengembalian bahan C-organik ke dalam tanah, hal ini menjadi salah satu sebab terjadinya penurunan produktivitas meskipun jenis dan dosis pupuk kimia ditingkatkan, karena tanah telah rusak. Salah satu cara untuk menambah C-organik pada tanah yaitu dengan ditambahkan pupuk organik.

Bahan organik dapat memperbaiki struktur tanah, meningkatkan kapasitas menahan air, pori aerasi, dan laju infiltrasi, serta memudahkan penetrasi akar, sehingga produktivitas lahan dan hasil tanaman dapat meningkat (Kementeriaan Pertanian, 2011). Beberapa jenis pupuk organik yang dapat dimanfaatkan dan mudah didapatkan adalah pupuk organik yang berasal dari kotoran hewan yang 
telah tercampur dengan alas kandangnya seperti pupuk kandang ayam, sapi dan domba.

Penggunaan pupuk organik selain diaplikasikan secara mandiri dapat juga diaplikasikan bersamaan dengan pupuk lain seperti pupuk hayati. Pupuk hayati mampu berperan dalam mengefisiensikan penggunaan pupuk organik. Salah satu pupuk hayati yang dapat digunakan adalah mikoriza. Mikoriza merupakan jenis jamur atau fungi yang bermanfaat bagi tanaman. Penambahan mikoriza pada tanah dapat membantu tanaman dalam menjangkau unsur hara, terutama $\mathrm{P}$ dan menjangkau ketersediaan air. Mikoriza yang digunakan dalam penelitian ini adalah Fungi Mikoriza Arbuskula (FMA).

Mengingat kebutuhan tanaman jagung terhadap unsur yang cukup tinggi, maka pupuk yang dapat digunakan adalah pupuk kandang sapi, ayam, domba dan Fungi Mikoriza Arbuskula. Pengujian ini dimaksudkan untuk memberikan gambaran pengaruh dan manfaat pupuk tersebut terhadap C-organik tanah, pertumbuhan dan hasil tanaman jagung semi (Zea mays, L. Varietas Pioner-2).

\section{METODE PENELITIAN}

Penelitian ini dilakukan di Desa Sukarasa, Kecamatan Samarang, Kabupaten Garut, Jawa Barat. Ketinggian tempat 1500 meter di atas permukaan laut dengan rata-rata curah hujan $48,6 \%$ termasuk kedalam tipe curah hujan $\mathrm{C}$, yaitu agak basah. Percobaan dilaksanakan pada Bulan Februari sampai April 2018. Bahan yang digunakan terdiri dari: benih jagung manis varietas pioneer-2, pupuk kandang ayam, pupuk kandang sapi, pupuk kandang domba dan Fungi Mikoriza Arbuskula (FMA). Sedangkan alat yang digunakan dalam percobaan terdiri dari: cangkul, tugal, meteran, kored/parang, timbangan analitik, alat tulis, penggaris, gelas ukur, gembor, jangka sorong, oven dan karung plastik.

Metode penelitian yang digunakan adalah metode eksperimental, dengan Rancanagan Acak Kelompok (RAK) berpola faktorial 3 x 3 dengan tiga ulangan Faktor pertama adalah dosis pupuk organik (o) dengan tiga taraf yaitu : $o_{1}$ (pupuk kandang ayam), $\mathrm{o}_{2}$ (pupuk kandang sapi), $\mathrm{o}_{3}$ (pupuk kandang domba) dan faktor kedua yaitu dosis mikoriza $(m)$ dengan tiga taraf yaitu : $\mathrm{m}_{1}(2 \mathrm{gr}), \mathrm{m}_{2}(4 \mathrm{gr}) \mathrm{m}_{3}(8$ gr). Variabel yang diamati meliputi C-organik, Tinggi tanaman, Luas daun dan 
Bobot tongkol. Analisis data menggunakan uji $\mathrm{F}$ pada taraf kepercayaan $95 \%$, dilanjutkan dengan uji jarak berganda Duncan (DMRT) bila terdapat pengaruh yang nyata.

\section{HASIL DAN PEMBAHASAN}

Berdasarkan hasil pengujian pemberian dosis pupuk organik dan FMA memberikan pengaruh nyata terhadap tinggi tanaman dan bobot tongkol jagung semi.

Tabel 1. Pengaruh Pupuk organik dan FMA terhadap tinggi tanaman.

\begin{tabular}{|c|c|c|c|}
\hline \multirow{2}{*}{ Perlakuan } & \multicolumn{3}{|c|}{ Rata-rata tinggi tanaman $(\mathrm{cm})$} \\
\hline & $7 \mathrm{HST}$ & 35 HST & $63 \mathrm{HST}$ \\
\hline \multicolumn{4}{|l|}{ Jenis pupuk organik } \\
\hline $\mathrm{O}_{1}=$ Ayam $210 \mathrm{~g} /$ tanaman & $3.72 \mathrm{a}$ & $23.6 \mathrm{a}$ & $89.56 \mathrm{a}$ \\
\hline $\mathrm{O}_{2}=$ Sapi $210 \mathrm{~g} / \mathrm{tanaman}$ & $5.14 \mathrm{ab}$ & $28.51 \mathrm{ab}$ & $103.86 \mathrm{ab}$ \\
\hline $\mathrm{O}_{3}=$ Domba $210 \mathrm{~g} /$ tanaman & $3.25 \mathrm{~b}$ & $16.79 \mathrm{~b}$ & $73.08 \mathrm{~b}$ \\
\hline \multicolumn{4}{|l|}{ Dosis mikoriza } \\
\hline $\mathbf{M}_{1}=2$ gram $/$ tanaman & $3.56 \mathrm{a}$ & $17.93 \mathrm{a}$ & $67.42 \mathrm{a}$ \\
\hline $\mathbf{M}_{2}=4$ gram/tanaman & $3.61 \mathrm{ab}$ & $21.19 \mathrm{ab}$ & $84.5 \mathrm{ab}$ \\
\hline $\mathrm{M}_{3}=8 \mathrm{gram} / \mathrm{tanaman}$ & $4.94 \mathrm{~b}$ & $29.79 \mathrm{~b}$ & $104.58 \mathrm{~b}$ \\
\hline
\end{tabular}

Keterangan: Angka rerata yang diikuti huruf yang sama tidak memberikan perbedaan nyata berdasarkan Uji Jarak Berganda Duncan pada taraf $5 \%$.

Berdasarkan hasil pengamatan tinggi tanaman, perlakuan jenis pupuk kandang dan FMA berpengaruh nyata. Angka rata-rata tertinggi ditunjukan oleh perlakuan $\mathrm{O}_{2}$ (pupuk kandang sapi) 10 ton/ha setara dengan $210 \mathrm{~g} /$ tanaman dan perlakuan $\mathrm{M}_{3}$ (FMA) $8 \mathrm{~g} /$ tanaman. Keadaan ini menunjukan bahwa pupuk kandang sapi dan FMA memberikan pengaruh yang nyata terhadap pertumbuhan tinggi tanaman jagung semi.

Perlakuan 10 ton/ha pupuk kandang sapi yang mengandung banyak unsur nitrogen yang sangat dibutuhkan oleh tanaman jagung telah mampu memacu pertumbuhan tinggi tanaman sampai titik optimum. Didukung oleh penelitian (Evanita dkk, 2012) Pemberian pupuk kandang sapi yang dikombinasikan dengan tumpangsari pada tanaman juga memberikan pengaruh terhadap tinggi tanaman terong, respon tersebut diduga berkaitan dengan kelebihan dari pupuk, kandungan 
yang dapat menaikan bahan serap tanah terhadap air dan membantu penyerapan hara dari pupuk kimia yang ditambahkan.

Mikoriza memberikan pengaruh yang nyata terhadap pertumbuhan tinggi tanaman jagung semi. hal ini diduga pada dosis tersebut enzim fosfatase tersedia dalam jumlah yang optimal dan seimbang maka mempengaruhi unsur yang sukar diserap oleh tanaman menjadi tersedia bagi tanaman dan memacu pertumbuhan pada tanaman, seperti yang dikemukakan oleh (Bolan 1991 dalam Musfal 2010) FMA bagi ekosistem adalah untuk menghasilkan enzim fosfatase yang dapat melepaskan unsur $\mathrm{P}$ yang terikat unsur $\mathrm{Al}$ dan Fe pada lahan masam dan Ca pada lahan berkapur sehingga $\mathrm{P}$ akan tersedia bagi tanaman).

Dengan demikian, baik pupuk kandang sapi ataupun keduanya berkontribusi terhadap peningkatan nilai tinggi tanaman.

Tabel 2. Pengaruh Pupuk organik dan FMA terhadap bobot tongkol

\begin{tabular}{lc}
\hline \multicolumn{1}{c}{ Perlakuan } & $\begin{array}{c}\text { Rata-rata bobot tongkol per } \\
\operatorname{tanaman}\left(\mathrm{cm}^{2}\right)\end{array}$ \\
\hline O1 = Ayam 210 g/tanaman & $94.17 \mathrm{a}$ \\
O2 = Sapi 210 g/tanaman & $97.52 \mathrm{a}$ \\
O3 = Domba 210 g/tanaman & $62.14 \mathrm{a}$ \\
\hline Dosis Mikoriza & \\
M1 = 2 gram/tanaman & $62.23 \mathrm{a}$ \\
M2 = 4 gram/tanaman & $65.54 \mathrm{ab}$ \\
M3 = 8 gram/tanaman & $126.06 \mathrm{~b}$ \\
\hline
\end{tabular}

Keterangan: Angka rerata yang diikuti huruf yang sama tidak memberikan perbedaan nyata berdasarkan Uji Jarak Berganda Duncan pada taraf $5 \%$.

Berdasarkan hasil pengamatan, penambahan FMA ke dalam tanah berpengaruh nyata terhadap bobot tongkol. Perlakuan $\mathrm{O}_{2}$ (pupuk kandang sapi) 10 ton/ha setara dengan $210 \mathrm{~g} /$ tanaman dan perlakuan $\mathrm{M}_{3}$ (FMA) $8 \mathrm{~g} /$ tanaman menunjukkan nilai bobot tongkol yang paling tinggi dibandingkan dengan perlakuan lainnya.

Penambahan pupuk anorganik berpengaruh nyata terhadap nilai K-potensial tanah. Nilai K-potensial yang paling tinggi ditunjukkan oleh perlakuan J. Pada prinsipnya unsur hara yang diberikan ke dalam tanah tersebut akan diserap oleh tanaman. Nilai K-potensial yang tinggi pada perlakuan J tersebut diduga berasal 
dari pupuk yang tidak diserap tanaman. Efisiensi pemupukan berbanding terbalik dengan residunya pada tanah, semakin tinggi residu (sisa) N, P, K pada tanah semakin rendah efisiensi pemupukan.

Tabel 3. Pengaruh Pupuk NPK majemuk 13:7:25 terhadap K-potensial Tanah

\begin{tabular}{|c|c|}
\hline Perlakuan & $\begin{array}{c}\text { K-potensial } \\
\left(\mathrm{mg} \mathrm{K}_{2} \mathrm{O} \cdot 100 \mathrm{~g}^{-1}\right) \\
\end{array}$ \\
\hline A = Tanpa Pupuk & $3,82 \mathrm{a}$ \\
\hline $\begin{aligned} \mathrm{B}= & 300 \mathrm{~kg} \cdot \mathrm{ha}^{-1} \text { Urea, } 150 \mathrm{~kg} \cdot \mathrm{ha}^{-1} \mathrm{SP}-36,50 \mathrm{~kg} \cdot \mathrm{ha}^{-1} \\
& \mathrm{KCl} \text { (NPK Standar) }\end{aligned}$ & $35,70 \mathrm{e}$ \\
\hline $\mathrm{C}=175 \mathrm{~kg} \cdot \mathrm{ha}^{-1} \mathrm{NPK}$ & $9,75 \mathrm{~b}$ \\
\hline $\mathrm{D}=350 \mathrm{~kg} \cdot \mathrm{ha}^{-1} \mathrm{NPK}$ & $12,95 \mathrm{bc}$ \\
\hline $\mathrm{E}=525 \mathrm{~kg} \cdot \mathrm{ha}^{-1} \mathrm{NPK}$ & $16,31 \mathrm{~cd}$ \\
\hline $\mathrm{F}=700 \mathrm{~kg} \cdot \mathrm{ha}^{-1} \mathrm{NPK}$ & $19,25 \mathrm{~d}$ \\
\hline $\mathrm{G}=875 \mathrm{~kg} \cdot \mathrm{ha}^{-1} \mathrm{NPK}$ & $18,47 \mathrm{~d}$ \\
\hline $\mathrm{H}=1050 \mathrm{~kg} \cdot \mathrm{ha}^{-1} \mathrm{NPK}$ & $36,11 \mathrm{e}$ \\
\hline $\mathrm{I}=700 \mathrm{~kg} \cdot \mathrm{ha}^{-1} \mathrm{NPK}+100 \mathrm{~kg} \cdot \mathrm{ha}^{-1}$ Urea & $34,80 \mathrm{e}$ \\
\hline $\begin{aligned} \mathrm{J}= & 700 \mathrm{~kg} \cdot \mathrm{ha}^{-1} \mathrm{NPK}+100 \mathrm{~kg} \cdot \mathrm{ha}^{-1} \text { Urea }+15 \mathrm{~kg} \cdot \mathrm{ha}^{-1} \\
& \text { SP-36 }\end{aligned}$ & $55,38 \mathrm{f}$ \\
\hline
\end{tabular}

Hasil pengamatan menunjukkan unsur N, P, dan K yang diberikan baik secara terpisah melalui pupuk anorganik tunggal maupun diberikan dalam bentuk pupuk anorganik majemuk, memberikan pengaruh yang nyata terhadap bobot tongkol jagung. Akan tetapi untuk pupuk anorganik majemuk, peningkatan tersebut baru terlihat mulai dari dosis pupuk majemuk $700 \mathrm{~kg} / \mathrm{ha}$. Perlakuan B, F, $\mathrm{G}, \mathrm{H}$, I dan $\mathbf{J}$ memberikan nilai yang berbeda nyata dibandingkan dengan perlakuan lainnya.

Tabel 4. Pengaruh Pupuk NPK majemuk 13:7:25 terhadap bobot tongkol jagung

\begin{tabular}{|c|c|}
\hline Perlakuan & Bobot Tongkol \\
\hline $\mathrm{A}=$ Tanpa Pupuk & $74,67 \mathrm{a}$ \\
\hline 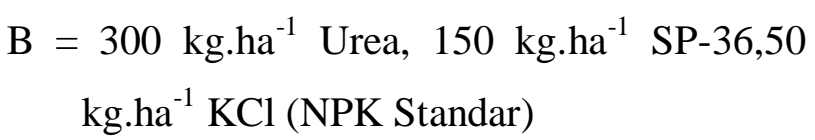 & $311,00 \mathrm{~b}$ \\
\hline $\mathrm{C}=175 \mathrm{~kg} \cdot \mathrm{ha}^{-1} \mathrm{NPK}$ & $107,33 \mathrm{a}$ \\
\hline
\end{tabular}




\begin{tabular}{|c|c|}
\hline Perlakuan & Bobot Tongkol \\
\hline$E=525 \mathrm{~kg} \cdot \mathrm{ha}^{-1} \mathrm{NPK}$ & $130,67 \mathrm{a}$ \\
\hline $\mathrm{F}=700 \mathrm{~kg} \cdot \mathrm{ha}^{-1} \mathrm{NPK}$ & $286,67 \mathrm{~b}$ \\
\hline $\mathrm{G}=875 \mathrm{~kg} \cdot \mathrm{ha}^{-1} \mathrm{NPK}$ & $282,00 \mathrm{~b}$ \\
\hline $\mathrm{H}=1050 \mathrm{~kg} \cdot \mathrm{ha}^{-1} \mathrm{NPK}$ & $325,33 \mathrm{~b}$ \\
\hline $\mathrm{I}=700 \mathrm{~kg} \cdot \mathrm{ha}^{-1} \mathrm{NPK}+100 \mathrm{~kg} \cdot \mathrm{ha}^{-1}$ Urea & $326,00 \mathrm{~b}$ \\
\hline $\begin{aligned} \mathrm{J}= & 700 \mathrm{~kg} \cdot \mathrm{ha}^{-1} \mathrm{NPK}+100 \mathrm{~kg} \cdot \mathrm{ha}^{-1} \text { Urea }+15 \\
& \mathrm{~kg} \cdot \mathrm{ha}^{-1} \mathrm{SP}-36\end{aligned}$ & $331,33 \mathrm{~b}$ \\
\hline
\end{tabular}

Keterangan: Angka rerata yang diikuti huruf yang sama tidak memberikan perbedaan nyata berdasarkan Uji Jarak Berganda Duncan pada taraf $5 \%$.

Pemberian pupuk NPK majemuk sesuai dosis anjuran menghasilkan nilai yang setara dengan pemberian $\mathrm{N}, \mathrm{P}$ dan $\mathrm{K}$ melalui pupuk anorganik tunggal. Dengan demikian penggunaan NPK majemuk dapat menjadi alternatif mengingat aplikasinya yang lebih efisien.

\section{KESIMPULAN}

Berdasarkan hasil pengujian pupuk NPK majemuk 13:7:25 terhadap tanaman jagung manis (Zea Mays, L.) varietas Talenta dapat disimpulkan bahwa perlakuan dosis pupuk majemuk mulai dari $175 \mathrm{~kg}$ sampai dengan $1050 \mathrm{~kg}$ per hektar berpengaruh nyata terhadap nilai N-total, P-potensial dan K-potensial tanah.

Dosis 700 kg.ha ${ }^{-1}$ NPK majemuk merupakan pilihan terbaik dalam meningkatkan bobot tongkol jagung manis (Zea Mays, L.) varietas Talenta.

\section{DAFTAR PUSTAKA}

Armaini, Wardati dan Zulfatri. 2011. Serapan N, P, K dan Produksi Jagung (Zea Mays) pada Tanah Gambut Bekas Bakar dengan Pemberian Thitonia Diversifolia sebagai Bahan Amelioran. Jurusan Agroteknologi Fakultas Pertanian Universitas Riau.

Kementerian Pertanian. 2011. Peraturan Menteri Pertanian Nomor 43/Permentan/SR.140/8/2011 tentang Syarat dan Tata Cara Pendaftaran Pupuk Anorganik. http://www.deptan.go.id (Diakses pada tanggal 29 Agustus 2017). 
Minardi, S., Winarno, J. dan Abdillah, A.H.N. 2009. Efek Perimbangan Pupuk Organik dan Pupuk Anorganik terhadap Sifat Kimia Tanah Andisol Tawangmangu dan Hasil Tanaman Wortel (Daucus carota L.).

Tisdale, S. W., J. L. Nelson, J Halvin. L., and J. D.Beaton. 1993. Soil Fertility and Fertilizer. Prentice Hall. New Jersey. Six Edition. 